\title{
An investigation of the thermal conductivity of snow
}

\author{
A. K. Singh \\ Institute of Armament Technology, Girinagar, Pune 411 025, India
}

\begin{abstract}
Thermal conductivity of snow has been investigated experimentally using the thermal-probe method, which is a transient method of measurement. The measurements have been made over a wide range of snow density (for fresh and dense snow), for varying temperatures and for different conditions of water content, snow-grain type, etc., both in the ficld and in the laboratory. The results are presented along with detailed sample descriptions. Thermal conductivity of snow increases with density and water content. It also increases with tempcrature, and the effect is more pronounced for temperatures between $-15^{\circ}$ and $0^{\circ} \mathrm{C}$.
\end{abstract}

\section{INTRODUCTION}

The thermal conductivity of snow is one of the parameters governing the encrgy exchange and thermal regime of a snow cover. Thus, accurate estimates of thermal conductivity of snow are important in the numerical simulation of heat transfer through a snow cover and in understanding the behaviour of the snow. Snow is a multiphase medium consisting of air, liquid water, water vapour and solid. The solid, arranged in various geometries, forms the ice skeleton, with voids between the solid grains and particles. The voids may contain either liquid water, water vapour, air or all of these. The components of heat conduction in natural snow cover are (i) conduction through the ice skeleton, (ii) conduction through pore space, and (iii) latent-heat transport across pore space due to vapour sublimation and condensation.

The ice skeleton provides a much better path for heat transfer than the pore space since the thermal conductivity of ice is about 100 times that of air/vapour. Thus, the temperature gradient must exist largely across the pore spaces, and is responsible for the transport of water vapour. The flux of vapour duc to molecular diffusion also depends on the vapour density gradient that develops due to tempcrature gradients. In addition, an evaporation-condensation process occurs among particles of high local temperature gradients of inter-particle structure (clusters and chains of grains providing high heat conduction). New grains may grow into pores at the expense of source grains (evaporation). New ice ice contacts in pores may act as short circuits to the flow of heat. At the same time, the ice grains hinder watcr-vapour diffusion. For low-density snow, conduction through air and transfer of latent heat is probably important. In high-density snow, the porosity is less as are temperature differences among neighbouring grains, so conduction through the ice lat tice may dominate the heat-transfer processes.

Because of the complexity of the heat-transfer processes, the thermal conductivity of snow is generally taken as "effective" conductivity, to account for the effect of all heattransfer processes, and its magnitude depends on snow density, frcc-watcr content, tempcraturc, compactness and microstructure. The experimental data of Pitman and Zuckerman (1967) show the expected trends with temperature; but the magnitude of change in effective thermal con- ductivity with temperature that they observed is too high to be explained by the temperaturc dcpendence of the vapourdiffusion term. Estimates of heat transport by vapour are in the range 10-40\% (Yosida and others, 1955; Yen, 1965; Arons, 1994), depending on the type of snow and its temperature. In some thermal-conductivity relations, a term is included for vapour diffusion (Morris, 1983).

Considerable scatter in the measured values of effective thermal conductivity has been reported in the literature. This has been related to vapour transport (Yosida and Iwai, 1954; Maeno and others, 1986; Fukusako, 1990; Colbeck, 1993). Water vapour may be responsible for some of the scatter but there are other causes. It has been shown that variations in snow microstructure are responsiblc for some of the variations in thermal conduclivity (Mellor, 1977; Arons, 1994; Arons and others, 1994; Sturm and others, 1997). Albert and McGilvary (1992) suggested that water vapour transfers a very small amount of heat, although this result is analytical, not experimental. The reported values of thermal conductivity may also vary due to different methods of measurement, i.e transient or steady-state, as pointed out by Sturm and others (1997).

As a way of mcasuring thermal conductivity, steady-state methods are simple in theory, but their practical application involves an elaborate expcrimental sct-up, including the thermal-guard system (Pitman and Zuckerman, 1967) to eliminate lateral heat flow. The effect of moisture migration is also a problcm duc to prolonged steady-state temperature gradients imposed on a test sample. A large test sample is required for such measurements. Moreover, these methods do not permit in-situ measurement. For any thermal-conductivity measurement, a measurable steady-state or transient temperature gradient is imposed on the sample. If the sample is dry the imposed gradicnt can bc largc and therefore can be measured accurately. But in the case of moist materials, a temperature gradient causes moisture migration, which may result in large errors in the estimation of thermal conductivity. All these disadvantages of steady-state methods can be overcome by using a transient method. In this study, the transient-probe method (or needle-probe method) has been used to determine the thermal conductivity of snow.

Jaafar and Picot (1970) were the first to use the needle- 
probe method to measure thermal conductivity of snow. Lange (1985) measured effective thermal conductivity along with a stratigraphy profile and presented the results as a function of density. Thermal-conductivity measurements made by Sturm and Johnson (1992) wore mainly for depth hoar. Existing studies on the thermal conductivity of snow are revicwed by Sturm and others (1997), who highlight the limitations of earlier studies and point out that the key attributes of snow thermal conductivity are temperature and microstructure.

Variation of thermal conductivity with temperature is another important aspect of the heat-transport mechanism, but relevant experimental data are sparse (Sturm and others, 1997). The present paper provides more information about the influence of temperature on thermal conductivity and is intended to contribute to the development of a data bank containing detailed information on snow conditions and temperatures when measurements were made.

The thcrmal-conductivity rclations (generally thermal conductivity as a function of density) available in literature are mostly empirical and have been derived through curvefitting from measured values, or in some cases derived from geometric models developed for other materials isoils, powders, etc.). These have achicved only partial success for the full range of density and snow conditions. There is no substitute for experimental data for heat-transport analysis. Discussions on heat transport in snow include Yosida and others (1953), de Quervain (1973), Mellor (1977), Yen (1981), Morris (1983) and Arons and Colbeck (1995). Yosida and others (1955) derived formulae for the contributions of moist air and ice to heat flow through the aggregate, and suggested that the two constituents could be considered as a hybrid of series and parallel processes. They used the concept from optics to provide an index of parallelism, but did not provide a practical solution. Arons (1994) provides a comprehensive revicw of gcometric snow models. Adams and Sato (1993) and Arons and Colbeck (1995) attempted to correlate effective thermal conductivity and microstructurc. Adams and Sato considered snow to be composed of uniform spheres of ice. The effect of liquid-water content and temperature was not accounted for. It is cssential that free-water content in snow should be considered along with temperature or microstructure, because it also contributes to the change in thermal behaviour of snow. Water provides a much better path for heat conduction when present in snow than when present in air. This relationship may not be simple and warrants extensive study.

This paper deals with the measurement of thermal conductivity of different types of snow using a transient thermal-probe method under varying conditions of density, liquid-water content, microstructure, temperature, etc. The probes used were self-designed, developed and calibrated in the laboratory. The main objective of this investigation is to develop a data bank of snow thermal-conductivity values for which detailed sample descriptions are also available.

\section{MEASUREMENT OF THERMAL CONDUGTIVITY}

One of the most widely used methods of measuring thermal conductivity of a porous media is the transient thermalprobe method (Steinmanis, 1982). The main problem to be overcome during experimental determination of effective thermal conductivity is that of water-content changes during the test. As discussed earlier, for any thermal-conductivity measurement a measurable steady-state or transicnt temperature gradient is imposed on the sample. If the sample is dry, the imposed gradient can be large, so that it can be measured accurately using simple instrumentation. In the case of snow, being in the vicinity of the melling point, a temperaturc gradient results in moisturc migration, and melting of snow may even occur, which may cause large errors in the thermal-conductivity measurement. 'lo avoid such errors, two requirements must be met. Firstly, the temperature rise must be small, and secondly, long run times must be avoided. Because of the first requirement, scnsitive instrumentation is needed to record the change in temperature.

Thermal probes are metallic cylinders in which a constant power heater and a temperature sensor are embedded. After being buried in the sample the probe is allowed to come to thermal equilibrium with the medium, and the power is switched on. The tempcrature of the cylinder rises and heat is dissipated into the surrounding medium. The rate of heat dissipation is a function of the thermal conductivity of surrounding material, among other factors. Therefore, provided the variation of probe temperature with time is recorded, the thermal conductivity of snow can be evaluated. This method of analyzing recorded time-temperature data is derived as follows. At uniform tempcraturc, bcginning at time $t=0$, heat is released by this source at a rate of $q$ per unit source length. 'The temperature $T$ (above the initial temperature) at a distance $r^{\prime}$ from the line source of heat is given as a function of time $t$ by the following equation (Carslaw and Jacger, 1959):

$$
T(r)=-\frac{q}{4 \pi \lambda} E_{\mathrm{i}}\left(-\frac{r^{\prime 2}}{4 \alpha t}\right)
$$

where $\lambda$ is thermal conductivity, $\alpha$ is thermal diffusivity and $E_{\mathrm{i}}$ is the exponential integral. For large time $t$, the cxponential integral can be approximated by a series expansion

$$
T(t)=\frac{q}{4 \pi \lambda}\left[\ln \left(\frac{4 \alpha t}{r^{\prime 2}}\right)-\ln \gamma+\frac{r^{\prime 2}}{4 \alpha t}-\frac{1}{4}\left(\frac{r^{\prime 2}}{4 \alpha t}\right)^{2}+\ldots\right] \text {, }
$$

where $\gamma$ is Euler's constant. Neglecting terms of the order of $1 / t$ and higher in Equation (2), gives

$$
\begin{aligned}
& T(t)=\frac{q}{4 \pi \lambda}\left[\ln \left(\frac{4 \alpha t}{r^{\prime 2}}\right)-\ln \gamma\right] \\
& T(t)=\frac{q}{4 \pi \lambda}\left[\ln t+\ln \left(\frac{4 \alpha}{r^{\prime 2}}\right)-\ln \gamma\right] .
\end{aligned}
$$

For fixed values of $r^{\prime}$ and $\alpha$, the temperature increases logarithmically with time. It is apparent from Equation (4) that if the temperature at the surface $r^{\prime}$ is plotted as a function of $\ln t$, the slope is $q / 4 \pi \lambda$, from which thermal conductivity can be determined. At any point in the medium, the temperature $T_{1}$ at time $t_{1}$ can be related to the tempcrature rise $T_{2}$ at any time $t_{2}$, by the following equation:

$$
T_{2}-T_{1}=\frac{q}{4 \pi \lambda} \ln \left(\frac{t_{2}}{t_{1}}\right) .
$$

If the probe is considered to be a line heat source, then Equation (5) is valid, and the value of $r^{\prime}$ becomes immaterial. This assumption is generally made in calculations. In the determination of thermal conductivity, the temperature rise during the first few seconds is neglected in order to eliminate spurious effects associated with contact resistance and 
warming-up of the probe. More details about probe theory, its applications and limitations can be found in Blackwell (1954), de Vries and Peck (1958), Jaeger (1958), Ewen and Thomas (1987), Singh and others (1990) and Sturm and Johnson (1992). Ewen and Thomas (1987) is an in-depth analysis of the thermal-probe method.

The probe was calibrated by performing laboratory tests for glyccrol, which was considered suitable because contactresistance errors can be neglected when the probe is in liquid. Since glyccrol is a viscous liquid, convective-heat flow effects are also minimized. The conductivity of glycerol was estimated to be $6-7 \%$. The thermal probe was made of a thin stainless-steel needle, was $134 \mathrm{~mm}$ long and $1.2 \mathrm{~mm}$ in diameter, and had a thread-insulated constantan resistance heater wire (36 gauge) and enamelled copper-constantan thermocouple (32 gauge) up to its midpoint to sense the temperature changc. A d.c. power supply was used to supply constant current $( \pm 0.1 \mathrm{~m} \Lambda)$ to the probe heater. To record the temperature change, a 6.5 digit Hewlett Packard multimeter was used.

To start the test, power is switched on when the probe temperature becomes stable. The tempcrature of the probe is recorded at each $5 \mathrm{~s}$ interval up to 34 min duration. The probe current is chosen such that the overall rise in temperature during the experiment is $\left\langle 4-5^{\circ} \mathrm{C}\right.$. From the slope of the temperature time curve (time on natural logarithm scale), thermal conductivity is calculated using the leastsquares curve-fitting technique on a desktop computer. For each sample, two tests werc conducted after allowing the probe enough time to attain thermal equilibrium. The average of the two readings is the thermal conductivity of the test sample. For the thermal-conductivity values of snow reported in this paper, the order of error in the measurement is $<10 \%$. The tests were carried out both in the field (two locations) and in the laboratory from 1993 to 1996. $\Lambda$ t one field location the ambient temperatures were quite low (minimum $-30^{\circ} \mathrm{C}$ ), while at the other location they were moderate (minimum $-10^{\circ} \mathrm{C}$ ). The results reported were for low or negligible wind-activity periods, and some of the tests were conducted during weekly stratigraphy measurements inside the pit by inserting the probe horizontally to avoid the effect of snowpack temperature gradients. Laboratory tests were conducted in a walk-in cold chamber under conditions of controlled temperature and humidity. The test samples were collected (vertical sample) from the field and transported to the laboratory in pre-cooled containers by helicopter.

Tables 1-3 present some of the test results for different types of snow, along with sample descriptions. Equi-tcmpcrature (ET) refers to rounded grains, temperature gradient (TG) to depth-hoar grains, sugar grain to cubic or hexagonal typc of grains and MF to the melt-freeze cycle of snow.

\section{RESULTS AND DISGUSSION}

Figures 1 and 2 show mcasured values of effective thermal conductivity of snow for a wide range of natural snow density which is a direct consequence of bonding and microstructure. Effective thermal conductivity of snow shows a strong dependence on snow density, and the data form a widely scattered ficld. The scatter in the values of thermal conductivity is the result of (i) natural variation in the conductivity of snow (phase volume, packing, grain-size and type), (ii) variation in $\lambda_{e}$ with temperature, and (iii) measurement error. The increase in thermal conductivity of snow

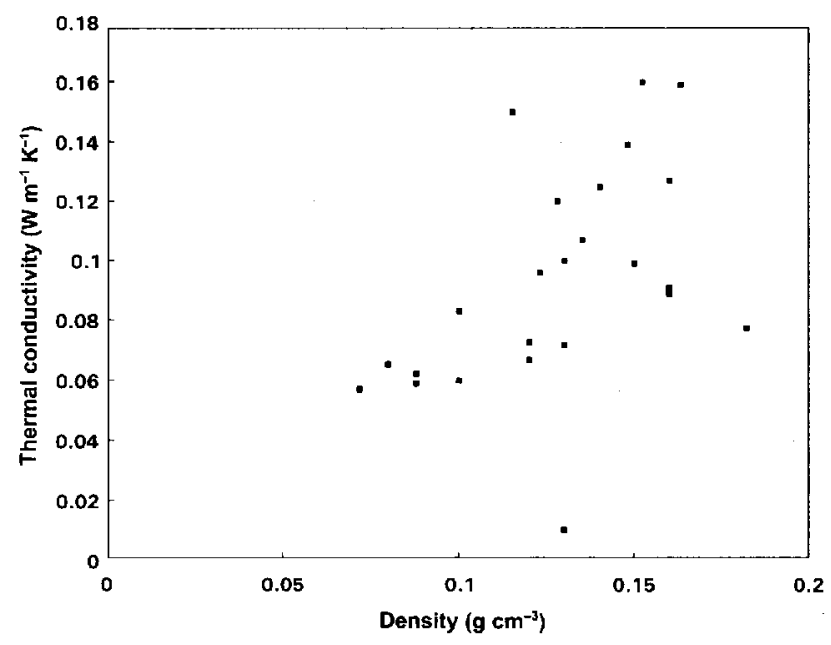

Fig. 1. Variation of measured effective thermal conductivity of dry snow with density.

Table 1. Measured thermal conductivity with densily (Jield study)

\begin{tabular}{|c|c|c|c|c|c|c|}
\hline \multirow[t]{2}{*}{ Sample $V_{0}$} & $\begin{array}{c}\text { Density } \\
\rho_{\mathrm{s}}\end{array}$ & Temperature & $\begin{array}{c}\text { Thermal } \\
\text { conductivity }\end{array}$ & Snote characteristics & Free-ierater content & \multirow[t]{2}{*}{ Comment } \\
\hline & $\operatorname{gcm} 3$ & $0^{\circ} \mathrm{C}$ & $\mathrm{Wm}^{\mathrm{l}} \mathrm{K}^{\mathrm{l}}$ & & $\%$ volume & \\
\hline 1 & 0.16 & 0.0 & 0.078 & Fresh, felt (2 days old) & 0.39 & - \\
\hline 2 & 0.17 & 0.0 & 0.113 & Fresh, Fil 3 days old) & 0.53 & - \\
\hline 3 & 0.17 & 0.0 & 0.29 & Fresh, ET (3 days old) & 1.65 & \\
\hline 5 & 0.196 & -0.1 & 0.110 & El' medium-soft & 1.43 & - \\
\hline 6 & 0.196 & 2.6 & 0.113 & ET, soft & 0.19 & \\
\hline 7 & 0.228 & -3.5 & 0.073 & ET, soft & 0.05 & Value not convincing \\
\hline 8 & 0.262 & -3.7 & 0.362 & ET, modium-soft & 0.0 & - \\
\hline 9 & 0.27 & -3.2 & 0.35 & El, medium-sofi & 0.0 & - \\
\hline 10 & 0.29 & 3.0 & 0.43 & ET, medium-soft & 0.0 & \\
\hline 11 & 0.30 & -2.7 & 0.438 & ET, medium-soft & 0.0 & - \\
\hline 12 & 0.30 & -2.2 & 0.43 & ET, compact & 0.0 & - \\
\hline 14 & 0.34 & -0.2 & 1.279 & MF, sugar grain, moist & 0.299 & - \\
\hline 15 & 0.358 & -0.2 & 1.028 & $\mathrm{MF}$, sugar grain, moist & 0.033 & - \\
\hline 16 & 0.34 & -0.2 & 0.985 & MF, medium-hard & 0.0 & - \\
\hline 17 & 0.375 & -0.2 & 1.095 & MF, medium-hard & 0.0 & \\
\hline
\end{tabular}


Table 2. Measured thermal conducivily with density for different twpes of snow grain (field study)

\begin{tabular}{|c|c|c|c|c|c|}
\hline \multicolumn{2}{|c|}{ FI } & \multicolumn{2}{|c|}{$T G$} & \multicolumn{2}{|c|}{ Sugar srain } \\
\hline $\begin{array}{l}\text { Density } \rho_{s} \\
\mathrm{gcm}^{3}\end{array}$ & $\begin{array}{c}\lambda_{\mathrm{c}} \\
\mathrm{Wm}^{1}{ }^{1} \mathrm{~K}^{1}\end{array}$ & $\begin{array}{c}\text { Density } p \\
\mathrm{gcm}\end{array}$ & $\begin{array}{c}\lambda_{e} \\
\mathrm{Wm}^{1}{ }^{\mathrm{K}}{ }^{i}\end{array}$ & $\begin{array}{c}\text { Density } \rho_{\mathrm{s}} \\
\mathrm{gcm}^{-3}\end{array}$ & $\begin{array}{c}\lambda_{\mathrm{f}} \\
\mathrm{Wm}{ }^{1} \mathrm{~K}{ }^{1}\end{array}$ \\
\hline 0.072 & 0.052 & $0 . .327^{*}$ & 0.33 & 0.324 & 0.188 \\
\hline 0.088 & 0062 & $0.277^{*}$ & 0.173 & 0.302 & 0.197 \\
\hline 0.088 & 0.059 & $0.324^{*}$ & 0.182 & 0.339 & 0.288 \\
\hline 0.152 & 0.115 & $0.324^{*}$ & 0.19 & 0.363 & 0.267 \\
\hline 0.115 & 0.15 & $0.348^{*}$ & 0.324 & 0.302 & 0295 \\
\hline 0.148 & 0.139 & $0.33^{*}$ & 0.254 & 0.372 & 0.38 \\
\hline 0.13 & 0.10 & $0.339^{*}$ & 0.354 & 0.35 & 0.25 \\
\hline 0.128 & 0.12 & $0.336^{*}$ & 0.3 & 0.34 & 0.18 \\
\hline 0.164 & 0.177 & $0.346^{*}$ & 0.265 & 0.345 & 0.195 \\
\hline 0.248 & 0.225 & $0.33^{*}$ & 0.209 & $\begin{array}{c}0.293 \\
(2.5 \mathrm{~mm})\end{array}$ & 0.155 \\
\hline 0.276 & 0.373 & $\begin{array}{c}0.184 \\
4 \quad 6 \mathrm{~mm})\end{array}$ & 0.19 & $\begin{array}{cl} & 0.30 \\
1.52 .0 \mathrm{~mm}^{*}\end{array}$ & 0.135 \\
\hline 0.462 & 0.715 & & & $\begin{array}{c}0.405 \\
(1-1.5 \mathrm{~mm})^{*}\end{array}$ & 0.144 \\
\hline 0.302 & 0.266 & & & $\begin{array}{c}0.236 \\
\langle 0.5-1.0 \mathrm{~mm}\rangle\end{array} ;$ & 0.124 \\
\hline 0.3 & 0.237 & & & & \\
\hline 0.296 & 0.36 & & & & \\
\hline 0.316 & 0.445 & & & & \\
\hline
\end{tabular}

*Values for a ficld location where ambient temperature gocs below $-25^{\circ} \mathrm{C}$ value in parentheses indicates predominant grain-size)

with density occurs because with an increase in density, more ice particles are packed into a unit volume and the number of contact points between the particles increases. The increase in contact points provides an increased number of paths for heat flow and hence increases the effective thermal conductivity of snow. This can be confirmed by studying the variation of effective thermal conductivity with porosity. The relationship between thermal conductivity and densily can also be explained in terms of the complex relationship betwcen microstructure and density.

To correlate the effective thermal conductivity of snow with microstructure (the scale on which multigrain structure occurs) and to obtain the structural details of snow, stereological techniques (i.e. study of three-dimensional objects using two-dimensional analysis) can be applicd. Coordination number (i.e. the number of bonds per grain) is an important microstructural parameter and defines the snow-grain arrangement. It is a basic packing parameter

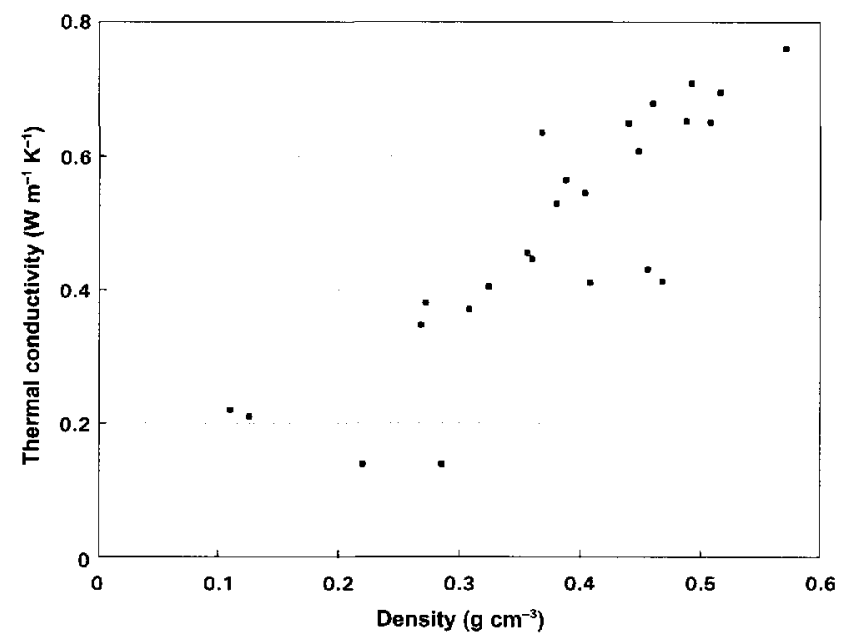

Fig. 2. Variation of measured effective thermal conductizity of snow with density.

that influences physical and mechanical properties of snow. It depends on the density, shape and size of grains and pore space present inside the material. Exact determination of coordination number can be a timc-consuming task. The number can be estimated accurately by measuring microstructure from closely spaced serial sections (thick and thin sections), but this is a complex job, and thus of limited practical application. One of the simplest ways to evaluate coordination number $N$, is to use the density-dependent equation used by Adams and Sato (1993):

$$
N=3.565-7.435 \phi_{\text {ice }}+24.825 \phi_{\text {ice }}^{2},
$$

wherc $\phi_{\text {ice }}$ is the ice-volume fraction, which can be written in simplified form as $\phi_{\text {ice }}=(1-$ porosity $)$ and has becn calculated from the relation

$$
\phi_{\text {icc }}=\frac{\rho_{s}}{\rho_{\text {ice }}},
$$

where $\rho_{\mathrm{s}}$ and $\rho_{\mathrm{ire}}$ are the densities of snow and ice, respectively. Figure 3 shows the variation of effective thermal conductivity with coordination number, using Equation $(6)$. Thermal conductivity is in general much greater for wellbonded snow.

Figure 4 shows measured values of the effective thermal conductivity with snow-pit observation (stratigraphy). Several measurements of effective thermal conductivity with stratigraphy werc taken, but only onc set of results is presented here. It can be observed that effective thermal conductivity of snow varies with Rammsonde (RAM) index, a

\begin{tabular}{|c|c|c|c|c|c|c|}
\hline $\begin{array}{c}\text { Sample } \\
\text { vo }\end{array}$ & Temperature & $\begin{array}{c}\lambda_{e} \\
E T, \text { fresh, dry } \\
\rho_{\mathrm{s}}=0.262\left(\mathrm{gcm}^{-3}\right)\end{array}$ & $\begin{array}{c}\lambda_{\epsilon} \\
E \Gamma, d y \\
\text { grain-size }=0.5 \cdot 1.0 \mathrm{~mm} \\
\rho_{\mathrm{s}}=0.44(\mathrm{gcm})\end{array}$ & $\begin{array}{c}\lambda_{e} \\
k T, d v \\
\text { grain-size }=0.51 .0 \mathrm{~mm} \\
\rho_{\mathrm{s}}=0.45\left(\mathrm{~g} \mathrm{~cm}^{-3}\right)\end{array}$ & $\begin{array}{c}\lambda_{e} \\
M F \\
\text { grain-size }=0.51 .0 \mathrm{~mm} \\
\rho_{\mathrm{s}}=0.15\left(\mathrm{~g} \mathrm{~cm}^{-3}\right)\end{array}$ & $\begin{array}{c}\lambda \\
T(\dot{r} \text { (broken }) \\
\rho_{\mathrm{s}}-0.44\left(\mathrm{gcm}^{3}\right)\end{array}$ \\
\hline & $\mathrm{C}$ & $W_{m}^{\prime} K^{1}$ & $W^{r} m^{1} \mathrm{~K}^{1}$ & $W_{m} K^{l}$ & $W m{ }^{1} K^{\prime}$ & $W m^{\prime} K^{\prime}$ \\
\hline 1 & -30 & 0.086 & 0.40 & 0.44 & 0.37 & 0.113 \\
\hline 2 & -25 & 0.103 & 0.37 & 0.40 & 0.33 & 0.111 \\
\hline 3 & 20 & 0.123 & 0.37 & 0.35 & 0.34 & 0.114 \\
\hline 4 & $\cdots 15$ & 0.115 & 0.35 & 0.32 & 0.31 & 0.121 \\
\hline 5 & -10 & 0.117 & 0.31 & 0.33 & 0.347 & 0.107 \\
\hline 6 & 5 & 0.179 & 0.32 & 0.31 & 0.349 & 0.115 \\
\hline
\end{tabular}

Table 3. Measured thermal conductivity with temperature (laboratory study) for different types of snow grain

Wites: Although the results are presented up to three decimal places, they are accurate to $\pm 0.01 \mathrm{~W}^{\mathrm{m}}{ }^{\mathrm{l}} \mathrm{K}{ }^{1}$. 


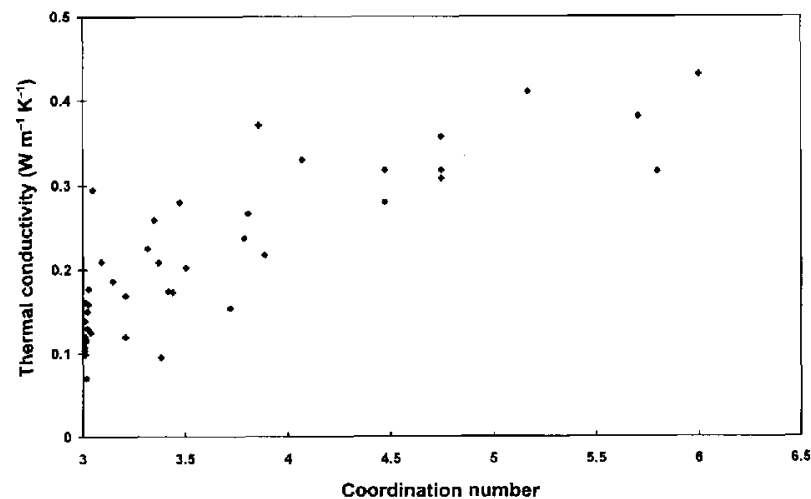

Fig. 3. Variation of effective thermal conductivily of snow with coordination number.

measure of snow hardncss/compactness, besides the other parameters mentioned abovc. The higher the RAM index, the higher the effective thermal conductivity of snow.

Figure 5 shows the effect of temperature on the thermal conductivity of ET and TG types of snow having densities of 0.262 and $0.28 \mathrm{~g} \mathrm{~cm}^{-3}$, respectively. Variation in thermal conductivity with temperature is presented, to separate the effects of temperature, density and type of grain. Most authors suggest that for snow with a density of $0.200 \mathrm{~g} \mathrm{~cm}^{-3}$, typical for depth hoar, the thermal conductivity (in the absence of convection) should lie in the ranges 0.10$0.20 \mathrm{~W} \mathrm{~m}{ }^{1} \mathrm{~K}^{11}$, but Albert and McGilvary (1992) reported values of $0.04-0.10 \mathrm{~W} \mathrm{~m}^{-1} \mathrm{~K}^{-1}$. Lange (1985) and Sturm and Johnson (1992) reported measured values of thermal conductivity of depth hoar (TG) in the ranges $0.04-0.05$ and $0.09-0.11 \mathrm{~W} \mathrm{~m}{ }^{1} \mathrm{~K}^{-1}$, respectively. In Figure 5, high valucs of effective thermal conductivity at $0^{\circ} \mathrm{C}$ are mainly due to

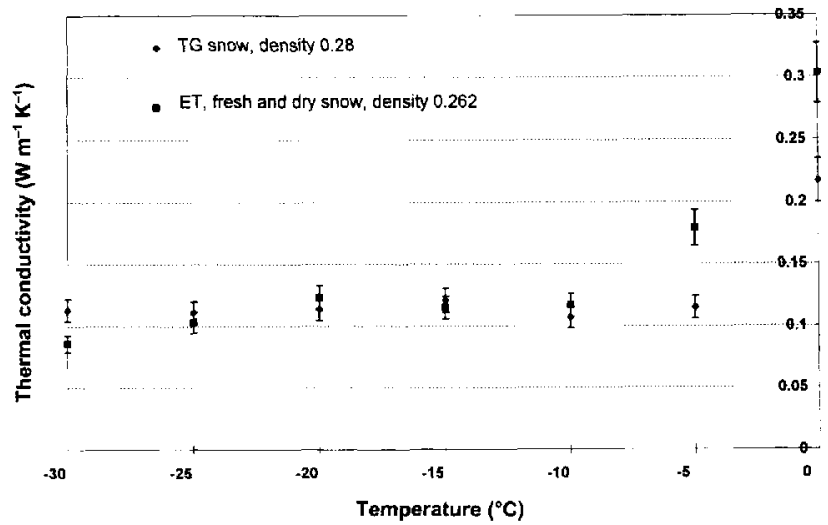

Fig. 5. Variation of measured effective thermal conductivity of ETand TG tppes of snow with temperature.

the presence of water/water vapour in snow. This effect can also be cxplained using vapour diffusion which depends on vapour pressure gradient and diffusion coefficient, both of which increase with temperature.

This variation of thermal conductivity with temperature is in agreement with the results of Sturm and others (1997) which are based on kinetic theory and the diffusion cquation for vapour transport (after Arons, 1994). This analysis points to the effect of vapour transport on snow thermal conductivity. As evident from cxperimental results presented here, at around $0^{\circ} \mathrm{C}$ the amount of vapour present in snow is high, so the effect of temperature is very marked. As temperature decreases towards $-30^{\circ} \mathrm{C}$, there is a decrease in the amount of vapour present in snow. Most of the change in thermal conductivity occurs between $0^{\circ}$ and $-15^{\circ} \mathrm{C}$.

To separate the cffect of water content from that of density, measurements were made for a constant-density snow

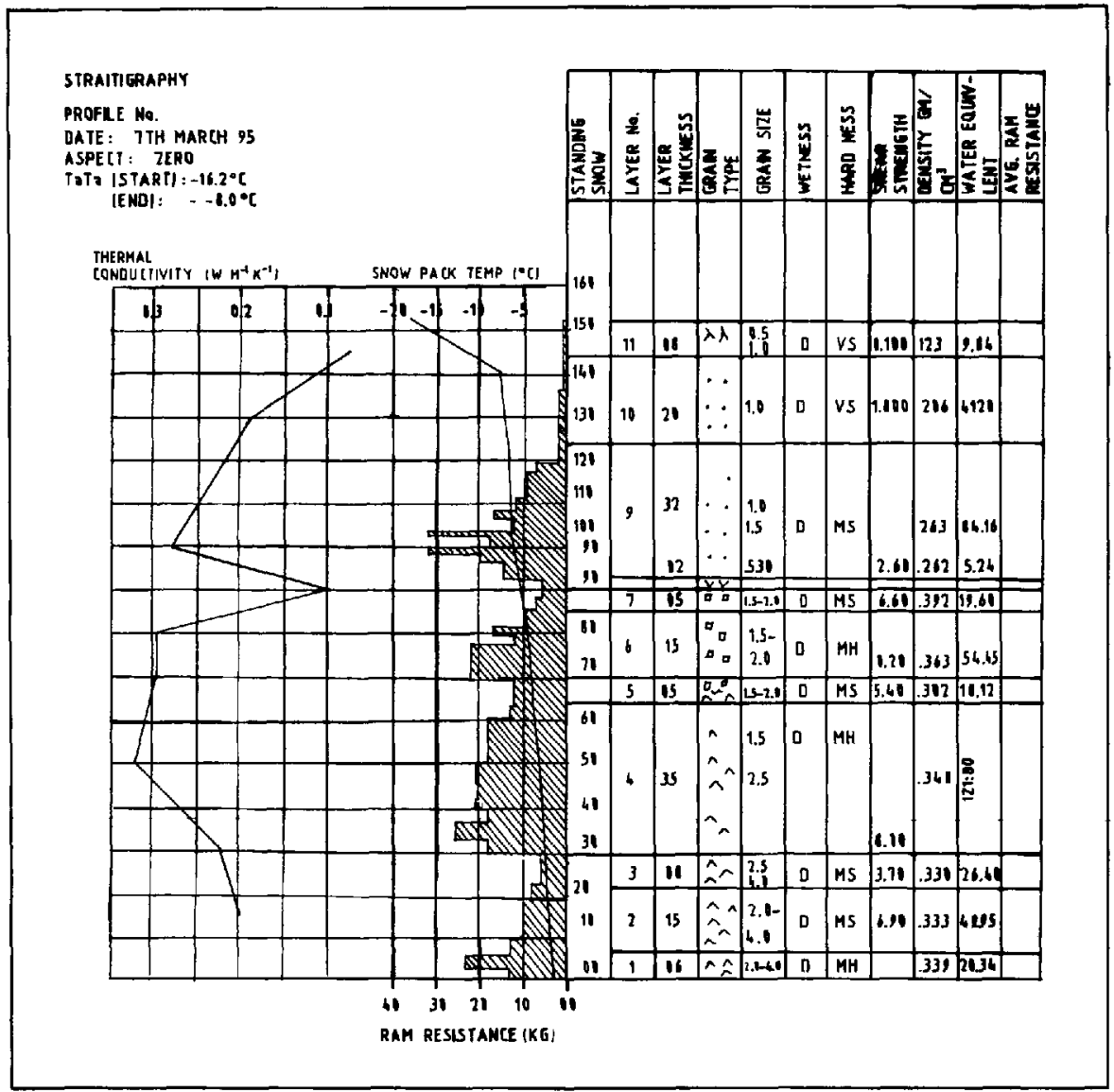

Fig. 4. Measured values of effective thermal conductivity presenled with stratigraphy profile. 
with varying water contents. Figure 6 shows the influence of free-water content in snow for a fixed-density snow. The frec-water content was measured using a dielectric capacitance meter. It can be seen that thermal conductivity of snow increases with watcr content. This can be explained by solid-liquid interaction. In snow the pore space is filled with air and liquid water. The liquid water forms thin film around the solid particles, and formation of wedges takes place, causing solid particles to touch each other at the wedge points, which increases the thermal conductivity of snow.

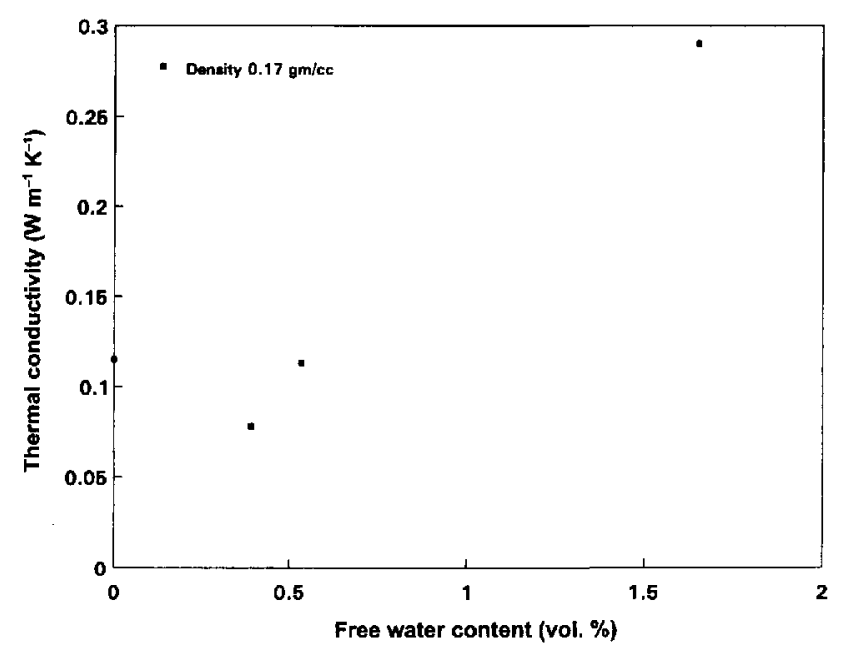

Fig. 6. Variation of effective thermal conductivity of snow with free-water content in snow for a snow density of $0.17 \mathrm{~g} \mathrm{~cm}^{-3}$.

The values reported here are lower than some of the results reported for similar density ranges. Measurements made in a natural environment include heat transport by solar radiation or convection, hence the higher values that tend to be reported in the literature. The snow conditions under which these measurements were made must also have been different. Few studies have reported the type of snow or the temperature in which the measurements were made, and as thermal conductivity is a function of temperature and snow texture as well as density, the cause of the discrepancy cannot be ascertained exactly. However, the values reported in the present paper are within the range obtained by Sturm and Johnson (1992). Based on the results of this study, as well as intuition and inferences from other studies, it appears that microstructure, free-water content (around $0^{\circ} \mathrm{C}$ ) and temperature play a vital role in determining the thermal conductivity of snow.

\section{ACKNOWLEDGEMENTS}

Thanks are due to the Dircctor, Snow and Avalanche Study Establishment (SASE), Manali, Himachal Pradesh, for facilitating this work, and to SASE personnel involved in the ficidwork. The author also thanks the Director, Institute of Armament Technology, Girinagar, Pune, for permission to publish this work.

\section{REFERENCES}

Adams, E. E. and A. Sato. 1993. Model for effective thermal conductivity of a dry snow cover composed of uniform ice spheres. Ann. Glaciol., 18, 300304

Albert, M. R. and W. R. McGilvary. 1992. Thermal effects due to air flow and vapor transport in dry snow. F. Glaciol., 38(129), 273-281.

Arons, E. M. 1994. Dependence of snow thermal and clcctrical conductivities on microstructure. (Ph.D. thesis, Dartmouth College.)

Arons, E. M. and S. C. Colbeck. 1995. Geometry of heat and mass transfer in dry snow: a review of theory and experiment. Rev. Genfiny. 33/4, 463-493.

Arons, E. M., S. C. Colbeck, W. R. McGilvary and V. F. Petrenko. 1994. Eflective medium approximation for snow thermal conductivity. In International Symposium on Snowe and Related Manifestations, 26-28 September 1994, Manali, India. Manali, India, Snow and Avalanche Study Establishment, 45-48. (Extended abstracts.)

Blackwcll, J. H. 1954. A transient-flow method for determination of thermal constants of insulating materials in bulk. F. Appl. Phys, 25, 137-144.

Carslaw, H. S. and J. C. Jaeger. 1959. Conduction of heal in solids. Second edition. Oxford, Clarendon Press.

Colbeck, S. C. 1993. The vapor diffusion cocfficient for snow. Water Resour Res., $29(1), 109115$.

de Quervain, M. R. 1973. Snow structure, heat, and mass flux through snow: International Association of Hydrological Sciences Publication 107 (Symposium at Banff 1972 - The Role of Snoz: and lee in Hydrology ), Vol. 1, 203-226.

de Vries, D. A. and A.J. Peck. 1958. On the cylindrical probe method of measuring thermal conductivity with special reference to soils. I. Extension of theory and discussion of probe characteristics. Aust. $\tilde{7}$. Phys., 11, $255-271$.

Ewen, J. and H. R. Thomas. 1987. The thermal probe: a new method and its use on an unsaturated sand. Géotechnique, 37 1), 91-105.

rukusako, S. 1990. Thermophysical properties of ice, snow, and sea ice. Int. $j$ Thermophys, $11(2), 353-372$.

Jaafar, H. and J.J. Picot. 1970. Thermal conductivity of snow by a transient state probe method. Water Resour. Res, 6(1), 333-335.

Jaeger, J. C. 1958. The measurement of thermal conductivity and diffusivity with cylindrical probes. Trans. Am. Geophys. Lnion, 39, 708 712.

Lange, M. A. 1985. Measurements of thermal parameters in Antarctic snow and firn. Ann. Glaciol., 6, 100-104.

Maeno, N., M. Fukuda and T. Kuroda. 1986. Structure and physical properties of snow and ice. Vol. 1. Tokyo, Kokon Shoin. [InJapanese.]

Mellor, M. 1977. Engineering properties of snow. 7. Glaciol., 19/81, 1566.

Morris, E. M. 1983. Modelling the flow of mass and energy within a snowpack for hydrological forecasting. Ann. Glaciol., 4, 198-203.

Pitman, D. and B. Zuckerman. 1967. Effect of thermal conductivity of snow at $-88^{\circ},-27^{\circ}$ and $-5^{\circ} \mathrm{C}$. 7. Appl. Phys, 38,6, 2698-2699.

Singh, A. K., R. Singh and 1). R. Chaudhary. 1990. Prediction of effective thermal conductivity of moist porous materials. F. Phys. D, 23, 698-702.

Steinmanis, J. E. 1982. Thermal property measurements using a thermal probe. In Underground cable thermal backfill. New York, Pergamon, 72-85.

Sturm, M. and J. B. Johnson. 1992. Thermal conductivity measurements of depth hoar. J. Geophys. Res., $97(\mathrm{~B} 2), 21292139$.

Sturm, M., J. Holmgren, M. König and K. Morris. 1997. The thermal conductivity of seasonal snow. F. Glaciol., 43(143), 26-41.

Yen, Y.-C. 1965. Effective thermal conductivity and water vapor diffusivity of naturally compacted snow. F. Geophys. Res., 70(8), 1821 - 1825.

Yen, Y.-G. 1981. Review of thermal properties of snow, ice and sea ice. CRREL Rep. 81-10.

Yosida, Z. 1955. Physical studies on deposited snow. I. Thermal propertics. Contrib. Inst. Low Temp. Sci., Ser. A 7, 19-74.

Yosida, Z. and H. Iwai. 1954. Measurement of the thermal conductivity of snow cover. SIPRE Transl. 30. 